
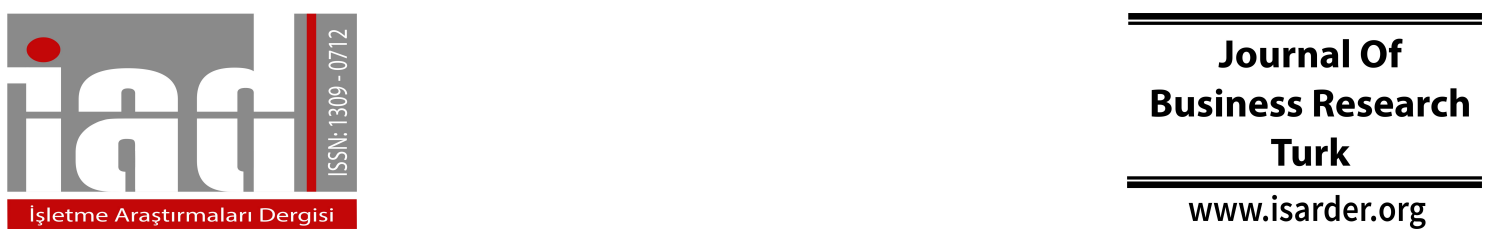

\title{
Türkiye'de Hisse Senedi Piyasası ve Ekonomik Gelişme İliş̧kisinin ARDL Sınır Testi Yaklaşımı ile Analizi \\ Analysing of the Relation Between Stock Markets and Economic Growth in Turkey by ARDL Bound Test
}

\author{
Umut Burak GEYİKÇi \\ Manisa Celal Bayar Üniversitesi, İşletme Fakültesi \\ Muradiye Kampüsü, Manisa, Türkiye \\ orcid.org/0000-0002-4285-2151 \\ umutburak.geyikci@cbu.edu.tr
}

\section{Özet}

$\mathrm{Bu}$ çalışma hisse senedi piyasası ile ekonomik gelişme arasındaki ilişkileri 1986 ile 2016 arasında, yıllık bazda incelemektedir. ARDL sınır testi ve Hata Düzeltme Terimi (ECT) vasıtasıyla değişkenler arasındaki uzun dönemli ilişkiler ve denge durumu belirlenmiştir. Sonuçlar hisse senedi piyasasının gelişimi ile ekonomik büyüme arasında uzun dönemde bir eşbütünleşme olduğunu göstermiştir. Kısa dönemli Granger nedensellik testi, GSYH ve para arzından hisse senedi piyasası gelişimine doğru iki yönlü bir nedensellik, özel sektör kredilerinden toplam dış ticarete yönelik tek yönlü bir nedensellik, para arzı ile toplam dış ticaret arasında iki yönlü bir nedensellik, GSYH'dan geniş para arzına yönelik de tek yönlü bir nedensellik bulunurken kısa vadede özel sektör kredilerine doğru herhangi bir nedensellik bulunamamıştır. Çalışma neticesinde, uzun vadede eşbütünleşik olan verilerin kısa vadede Schumpeter (1911)'de ortaya atılan görüşler yerine, Lewis (1954)'de ortaya atılan görüşlere daha yakın olduğu, ekonomik büyümeden finansal gelişime doğru bir akış yerine, karş1lıklı bir etkileşim içinde oldukları sonucu ortaya çıkarmıştır.

Anahtar Kelimeler: ARDL sınır testi, eşbütünleşme, Granger, hisse senedi piyasası, BİST

\section{Abstract}

This study investigates the relation between stock market and economic growth using yearly data between 1986 and 2016. Through the ARDL boundary test and the Error Correction Term (ECT), long-term relationships and equilibrium between variables were determined. The results showed that there was a long-term cointegration between the stock market development and economic growth. In the short-term Granger causality test, it has been concluded that the gross domestic product and money supply have two-way causality with stock exchange market, that there was one-way causality from private-sector loans to total external trade, that money supply has two-way causality with total foreign trade, that there was one-way causality from gross domestic product to money supply, that private sector loans had no causality with other sectors. In conclusion, the cointegrated variables are closer to the views of Lewis (1954) instead of Schumpeter (1911) and stock market capitalization has bilateral interaction with economic growth rather than a one-way flow from economic growth to stock market capitalization.

Keywords: ARDL bound test, cointegration, Granger, stock market, ISE 


\section{Giriş}

Türk Sermaye Piyasaları 1986 yılında Borsa İstanbul (BİST)'in açılması (o zamanki adı İstanbul Menkul Kiymetler Borsası-İMKB) ve yeni liberal ekonomik politikalarla birlikte 1980'lerin ortalarından itibaren finansal yapısını güçlendirmeye başlamıştır. Pek çok çalışmada kayıp yıllar olarak adlandırılan 1990'lardan sonra 2000'li yıllardan itibaren hızla ivmelenmeye başlayan sermaye piyasaları halen gelişmiş ülkelerde var olan derinliği yakalayamamıştır. Sermaye piyasaları tasarrufların mobil hale gelmesini kolaylaştırıp ekonomik büyüme için gerekli sermayeye dönüştürürken, reel sektörde meydana gelen değişimler de sermaye piyasalarını önemli derecede etkilemektedir. Sermaye piyasalarında meydana gelen gelişim, yatırımlar için gerek duyulan fonlara erişim maliyetini azaltırken, yabancı sermaye akışı ile mevcut fon büyüklüklerinin artışını da desteklemektedir. Bu açıdan ekonomik büyümenin finansal gelişme ile olan ilişsisini araştıran pek çok çalışmaya rastlamak mümkündür. Bunlardan finansal gelişme ile ekonomik büyüme ilişkisinin yönü itibariyle; Robinson (1952) ekonomik büyümeden finansal gelişime doğru bir akım olduğu, Schumpeter (1911) ise finansal gelişimden ekonomik büyümeye doğru bir akım olduğunu belirtmiştir (Özcan ve Arı, 2011). Bunlarla birlikte literatürde gerçekleştirilmiş olan çalışmalar temelde dört farklı hipotez üzerinde kurulmuşladır. Bunlardan ilki; finansal gelişmenin ekonomik büyüme üzerinde yüksek düzeyde etkisi olduğu (Patrick, 1966), ikincisi ekonomik büyümenin finansal gelişme üzerinde önemli derecede etkisi olduğunu savunan görüş (Robinson 1952), üçüncüsü finansal gelişme ve ekonomik büyüme arasında karş1lıklı bir etkileşim olduğu (Lewis, 1954) ve sonuncusu ise aralarında herhangi bir etkileşim olmadığını Lucas (1988), Meier ve Seers (1984), Stern (1989) savunan görüştür.

Literatürde finansal gelişmişlik ile ekonomik büyüme arasındaki ilişkileri ölçmek için; milli gelir, M1, M2 ve M3 para arzları, banka kredileri, gayri safi yurt içi hasıla, özel sektör kredileri, toplam krediler, hisse senedi piyasası kapitalizasyon oranı gibi değişkenler ile bunların birbirlerine oranları gibi farklı ölçüm materyalleri kullanılmıştır. $\mathrm{Bu}$ çalışmada ekonomik büyümenin hisse senedi piyasası üzerindeki etkisini ölçebilmek maksadıyla, Gökdeniz vd. (2003), Altunç (2008), Ghildiyal vd. (2015)' de kullanılana benzer değişkenler olan gayrisafi yurt içi hasıla (GSYH), özel sektör kredileri, hisse senedi piyasası kapitalizasyon oranı, M2 geniş para arzı ve toplam dış ticaret değişkenlerinin GSYH'ya oranları kullanılmıştır.

Ekonomik büyüme, bir ekonominin ürettiği mal ve hizmetlerdeki artışı ifade eder (Onwumeree vd. 2012). Ekonomik büyümenin gerçekleşebilmesi için diş ticaretin de gelişmesi gerekmektedir. Firmalar küresel pazarlarda geleneksel ve modern yöntemlerle yeni müşteriler bulmalı, bu sayede ekonomik büyümeye ve yurt içi gelirin artmasına katkıda bulunmalıdırlar (Metin, 2016). Vatandaşların (yatırımcılar) kişi başına düşen gelirlerinde bir artış, yatırımcıları maddi gelişime götüren finansal sistem mekanizması yoluyla birçok açıdan uzun vadeli finansal varlıklara yatırım yapmaya zorlayabilir. Finansal kalkınma ile ekonomik büyüme arasındaki bu ilişki son yıllarda yoğun bir şekilde incelenmiştir (Okeke ve Acha, 2017).

$\mathrm{Bu}$ çalışmanın amacı, ekonomiye ilişkin farklı değişkenlerin hisse senedi kapitalizasyon oranı ile olan ilişkilerini belirleyerek Schumpeter (1911)'de temeli atılmış olan ekonomik büyümenin finansal gelişme üzerine etkili olduğu görüşünü test etmektir. Gerçekleştirilen analiz neticesinde böyle bir etki çıkması durumunda çeşitlendirme firsatı arayan yatırımcılar, Türkiye gibi gelişmekte olan ülkelerde ekonomik göstergeler yardımıyla hisse senedi piyasalarına yapacakları yatırımları daha 
rahat öngörebileceklerdir. Diğer yandan ekonomik büyüme neticesinde vatandaşların kişi başı düşen gelirindeki artışın da onları hisse senedi piyasası yoluyla uzun vadeli yatırımlar yapmaya sevk edeceği düşünülmektedir. Bu bağlamda çalışmada kullanılan ARDL sınır testi yaklaşımı Türk ekonomisi açısından finansal gelişme ve ekonomik büyüme arasındaki ilişkileri araştırmak için kullanılmıştır.

\section{Literatür Taraması}

Schumpeter (1911) çalışmasında, kredi mekanizması aracılığı̆yla finansın, ekonomik büyüme üzerinde etkili olduğunu belirtmiştir. Bu yönüyle finansal gelişim ve ekonomik büyüme ilişkisinden ilk kez bahsedilmiştir. Diğer yandan literatürde finansal gelişimin ekonomik büyüme ile ilişkisine ilişkin ampirik kanıtları ortaya ilk koyan çalışma Goldsmith (1969)'dur. Goldsmith çalışmasında ekonomik büyüme ile finansal gelişim arasında kuvvetli ve pozitif yönde bir nedensellik ilişkisi olduğunu ifade etmiştir. Sonrasında özellikle Türkiye gibi gelişmekte olan ülkeler üzerinde gerçekleştirilen çalışmalardan Korajczyk (1996), uluslararası entegrasyonu olan hisse senedi piyasalarının ekonomik büyüme ile pozitif yönlü bir ilişkisi olduğunu bulgulamıştır. Levine ve Zervos (1998) çalışmalarında sermaye piyasalarındaki likidite durumu ve bankacılık sektörü ile ekonomik büyüme arasında doğrudan pozitif bir ilişki olduğunu bulgulamışlardır. Boubakari ve Jin (2010) likiditesi yüksek ve aynı zamanda hareketli hisse senedi piyasasına sahip ülkelerde, hisse senedi piyasası ile ekonomik büyüme arasında pozitif bir korelasyon olduğunu vurgulamışlardır. Seven ve Yetkiner (2016) gerçekleştirdikleri çalışmalarda inceledikleri 146 ülke içerisinde büyük ve likiditesi yüksek hisse senedi piyasaları ile ekonomik büyüme arasında pozitif bir korelasyon varken, küçük ve likiditesi düşük hisse senedi piyasaları ile ekonomik büyüme arasında anlamlı bir ilişki olmadığını bulgulamışlardır. Benzer şekilde Minier (2003) ile Rioja ve Valev (2004) çalışmalarında borsa gelişimi ile ekonomik büyüme arasında herhangi bir pozitif ilişki olmadığını ifade ederlerken, N'Zue (2006) çalışmasında ise hisse senedi piyasasından ekonomik büyümeye doğru tek yönlü bir nedensellik bulgulamıştır.

$\mathrm{Bu}$ çalışmada literatürde çoğunlukla yapılanın aksine hisse senedi piyasasının ekonomik büyüme üzerinde değil, ekonomik büyümenin hisse senedi piyasası üzerinde olası etkisi ölçülecektir, bu konuda Dettrey ve Palmer (2015) çalışmalarında ABD'de demokrat ve cumhuriyetçi başkanlar döneminde ekonomik büyümenin hisse senedi piyasası ve işsizlik üzerindeki etkisini ölçmüşler ve cumhuriyetçi başkanlar döneminde ekonomik büyümenin hisse senedi piyasasının gelişimini önemli ölçüde etkilediğini bulgulamışlardır.

\section{Materyal ve Metod}

Çalışmada, ekonomik büyümenin, hisse senedi piyasası üzerindeki etkisini ölçmek maksadıyla beş değişken kullanılmıştır. Hisse senedi kapitalizasyon oranı, hisse senedi piyasasını temsil ederken diğer dört değişken ise ekonomik büyümeyi temsil etmektedirler. Çalışmada kullanılan değişkenler şunlardır;

KBGSYH; Kişi başına düşen gayrisafi yurtiçi hasıla

GPGSYH; M2 geniş para arzının gayri safi yurt içi hasılaya oranı

HSPGSYH; "Hisse senedi piyasasının gelişim göstergesi" olarak kullanılan bu oran, hisse senedi piyasası kapitalizasyon değerinin gayrisafi yurt içi hasılaya oranıdır.

KRDGSYH; Bankacılık sektörünün göstergesi olarak kabul edilen bu oran özel sektör kredilerinin gayrisafi yurt içi hasılaya oranıdır. 
DTGSYH; ekonominin açıklığı göstergesi olarak kabul edilen bu oran toplam dış ticaret (ihracat+ithalat) rakamlarının gayrisafi yurt içi hasılaya oranıdır.

Serilerin lineer hale dönüşerek aykırı değerlerin etkisini azaltmak maksadıyla tüm serilerin logaritmaları alınmalıdır (Türe ve Akdi, 2005; Ayvaz Kızılgöl, 2011), bu nedenle tüm serilerin logaritmaları alınmıştır. Çalışmada kullanılan zaman serileri Borsa İstanbul'un faaliyete geçmiş olduğu yıl olan 1986'dan başlayarak 2016 y1lı sonuna kadar geçen süreyi yıllık değerlerle kapsamaktadır. Elde edilmiş olan verilerden KBGSYH, GPGSYH, KRDGSYH rakamları Dünya Bankası veri havuzundan, dış ticaret rakamları Türkiye İstatistik Kurumu (TÜIK) veri tabanından ve M2 Geniş para ise Türkiye Cumhuriyet Merkez Bankası (TCMB) veri tabanından alınmıştır.

Araştırma hedefleri doğrultusunda aşağıda belirtilmiş olan model oluşturulmuştur;

Finansal gelişme $=\mathrm{f}(\mathrm{KBGSYH})$.

Üstte belirtilmiş olan modelin ekonometrik formu aşağıdaki şekilde oluşturulmuştur;

HSPGSYH $_{\mathrm{t}}=\alpha+\beta_{1} \mathrm{GPGSYH}_{\mathrm{t}}+\beta_{2} \mathrm{KBGSYH}_{\mathrm{t}}+\beta_{3} \mathrm{KRDGSYH}_{\mathrm{t}}+\beta_{4} \mathrm{GTGSYH}_{\mathrm{t}}+\varepsilon \mathrm{t}$

Üstte verilmiş olan denklemde; $\alpha$ kesişim noktası ve $\beta 1-\beta 4$ açıklayıcı değişkenlerin katsayılarıdır.

Tablo 1.'de zaman serilerine ait açıklayıcı istatistikler ve Tablo 2.'de korelasyon tablosu yer almaktadir.

Tablo 1. Açıklayıcı Değişkenler KBGSYH GPGSYH HSPGSYH KRDGSYH DTGSYH

\begin{tabular}{lccccc}
\hline \hline Mean & 5,726367 & 3,522171 & 1,588723 & 3,212076 & 3,617047 \\
\hline Median & 5,609472 & 3,610918 & 1,386294 & 2,995732 & 3,610918 \\
\hline Maximum & 6,857514 & 3,806662 & 2,564949 & 4,248495 & 4,025352 \\
\hline Minimum & 4,330733 & 3,135494 & 0,693147 & 2,639057 & 3,178054 \\
\hline Std, Dev, & 0,816707 & 0,222272 & 0,663799 & 0,520296 & 0,262483 \\
\hline Skewness & $-0,006560$ & $-0,465573$ & 0,140600 & 0,845847 & 0,033022 \\
\hline Kurtosis & 1,644948 & 1,728819 & 1,507863 & 2,250484 & 1,705039 \\
\hline Jarque-Bera & 2,371938 & 3,207125 & 2,977995 & 4,422152 & 2,171660 \\
\hline Probability & 0,305450 & 0,201179 & 0,225599 & 0,109583 & 0,337621 \\
\hline Sum & 177,517400 & 109,187300 & 49,250410 & 99,574350 & 112,128500 \\
\hline Sum Sq, Dev, & 2,001031 & 1,482148 & 13,218880 & 8,121231 & 2,066916 \\
\hline
\end{tabular}

Tablo 2. Korelasyon Matrisi

KBGSYH GPGSYH HSPGSYH KRDGSYH DTGSYH

\begin{tabular}{lllllll}
\hline \hline KBGSYH & 1,000000 & & & & \\
\cline { 1 - 4 } GPGSYH & 0,890397 & 1,000000 & & & \\
\cline { 1 - 4 } HSPGSYH & 0,996323 & 0,904468 & 1,000000 & & \\
\cline { 1 - 4 } KRDGSYH & 0,862185 & 0,845243 & 0,887116 & 1,000000 & \\
\cline { 1 - 4 } DTGSYH & 0,801089 & 0,840208 & 0,804124 & 0,643438 & 1,000000 \\
\hline
\end{tabular}


İnceleme kapsamında yer alan serilerin tamamı trend içermektedir, Serilere ait trend grafikleri Grafik 1, 2, 3, 4 ve 5'te verilmiştir.

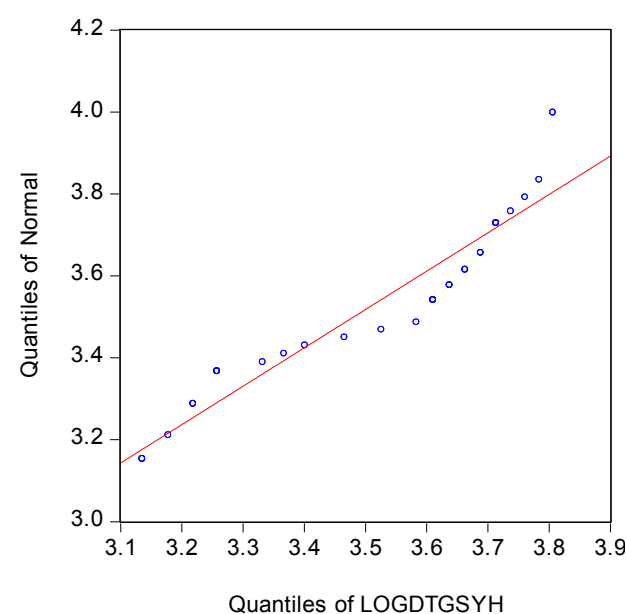

Grafik 1, DTGSYH

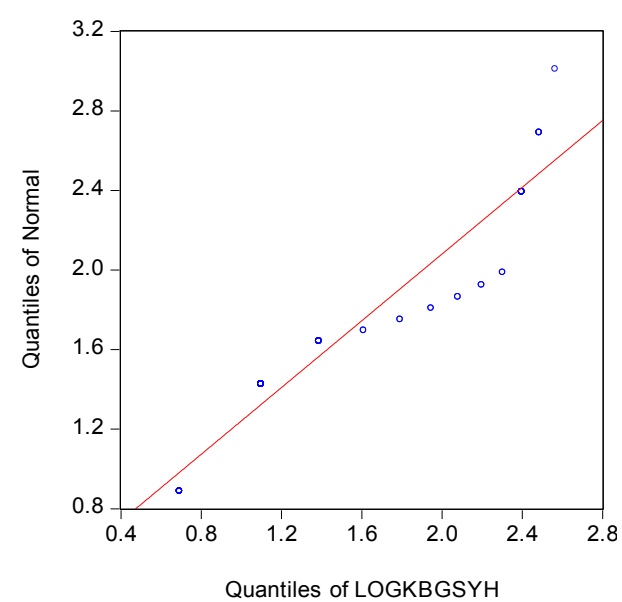

Grafik 3, KBGSYH

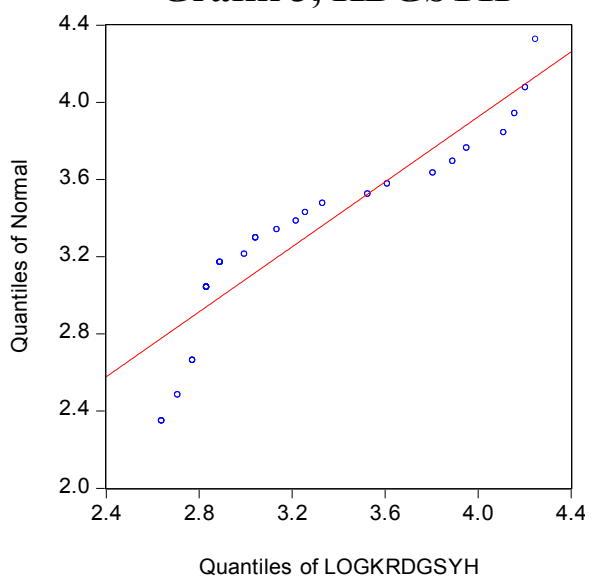

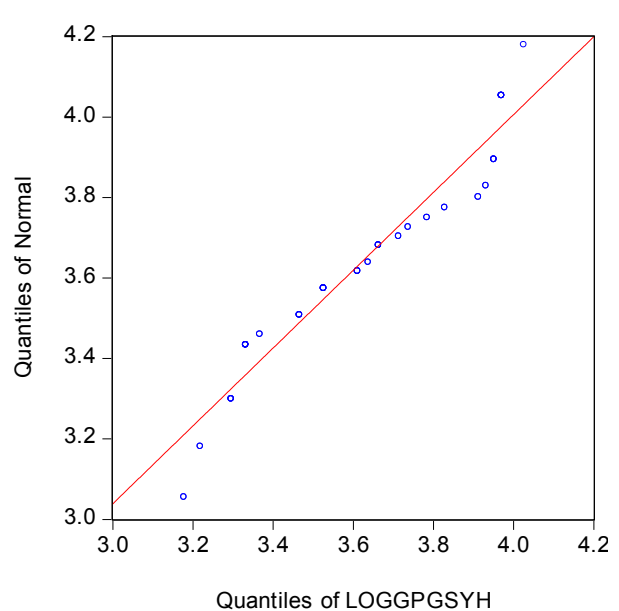

Grafik 2, GPGSYH

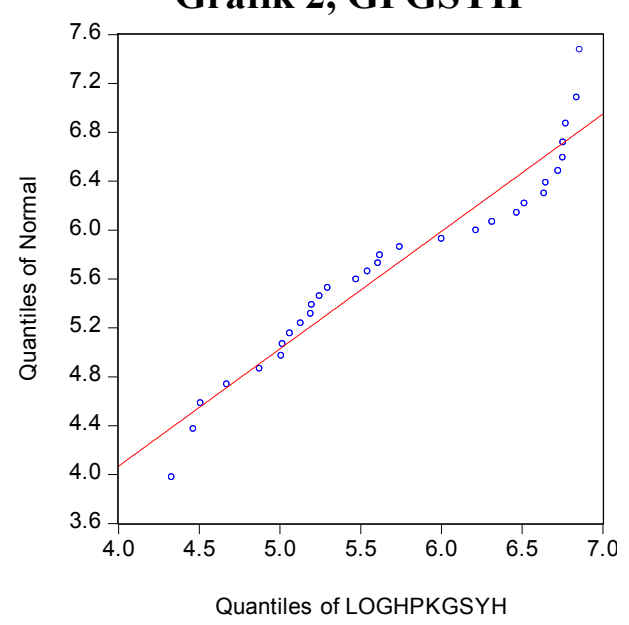

Grafik 4, HPKGSYH

\section{Grafik 5, KRDGSYH}

Gerçekleştirilmiş olan birim kök testleri Tablo 3.'te verilmiştir, ADF birim kök testinde $\mathrm{H}_{0}$ : Serinin birim kök içerdiğini, $\mathrm{H}_{1}$ ise serinin birim kök içermediğini belirtir, Tablo 3,'de yer alan ADF birim kök testi sonuçlarına göre düzeyde, trend ve sabit terimli t-istatistik değerleri GPGSYH için \%1 olasılıkla ve DTGSYH için \%5 olasılıkla birim kök içermediği için $\mathrm{H}_{0}$ hipotezi reddedilerek, serilerin durağan olduğu sonucuna 
ulaş1lırken, KBGSYH, HSPGSYH ve KRDGSYH serileri için aynı durum söz konusu olmamakta ve seriler düzeyde birim kök içermektedirler.

İncelenen serilerde durağanlık (birim kök) olup olmadığını test etmede kullanılan testlerden bir başkası da Kwiatkowski, Phillips, Schmidt, Shin (KPSS)'dir. Bu birim kök testi ADF'nin tam tersi şekilde çalışır, kurulacak olan hipotezlerde $\mathrm{H}_{0}$; serinin birim kök içermediğini, $\mathrm{H}_{1}$ ise serinin birim kök içerdiğini ifade eder, Tablo 3.'te gösterilmiş olan analiz neticesinde incelenen serilerin trend ve sabit terimli KPSS testi neticesinde KBGSYH, GPGSYH, HSPGSYH ve DTGSYH serilerden elde edilen LM istatistiği sonuçlarının Kwiatkowski-Philips-Schmidt-Shin (1992) değerlerinden küçük olmaları nedeniyle $\mathrm{H}_{0}$ hipotezinin kabul edilerek serilerin birim kök içermedikleri sonucuna ulaşılırken KRDGSYH serisi için elde edilen LM sonucunun Kwiatkowski-PhilipsSchmidt-Shin (1992) değerlerinden büyük olması nedeniyle, $\mathrm{H}_{0}$ reddedilerek seride birim kök olduğu sonucuna ulaşılmıştır.

Her iki birim kök test sonucundan elde edilen değerler GPGSYH ve DTGSYH serileri için düzeyde birim kök olmadığını rahatlıkla ifade etmemize olanak sağlarken, diğer seriler için düzeyde birim kökün var olduğu dolayısıyla birinci farklarını alarak tekrar kontrol etmemiz gerektiği sonucunu doğurmaktadır.

Tablo 3. Birim Kök Testleri

DÜZEY

ADF

KPSS

\begin{tabular}{|c|c|c|c|c|}
\hline \multirow[b]{3}{*}{ KBGSYH } & \multicolumn{2}{|c|}{ Trend ve Sabit Terimli } & \multicolumn{2}{|c|}{ Trend ve Sabit Terimli } \\
\hline & t-istatistiği & olasılık & & LM İstatistiği \\
\hline & $-2,5887$ & $0,2875^{*}$ & & 0,108382 \\
\hline GPGSYH & $-4,3788$ & 0,0082 & & 0,06473 \\
\hline HPKGSYH & $-2,3762$ & $0,3835^{*}$ & & 0,076564 \\
\hline KRDGSYH & $-1,2887$ & $0,8714^{*}$ & & $0,172981 *$ \\
\hline DTGSYH & $-3,7950$ & 0,0315 & & 0,066865 \\
\hline 1\% düzey & $-4,2967$ & & 1\% düzey & 0,216 \\
\hline $5 \%$ düzey & $-3,5684$ & & $5 \%$ düzey & 0,146 \\
\hline $10 \%$ düzey & $-3,2184$ & & $10 \%$ düzey & 0,119 \\
\hline
\end{tabular}

*durağanlık koşulunu sağlamamaktadır

Tüm seriler düzeyde (birim kök) durağanlık koşulu sağlamadıkları için 1, Farkları alınarak tekrar ADF ve KPSS birim kök testine tabi tutulmuşlardır, Elde edilen sonuçlar neticesinde ADF birim kök testi için tüm serilerin \%1 anlamlılık düzeyinde durağan olduğu sonucuna ulaşılmıştır.

KPSS birim kök testi açısından ise KBGSYH, HSPGSYH ve KRDGSYH serileri durağan hale gelirken, düzeyde durağan olan GPGSYH ve DTGSYH serileri durağanlık özelliklerini kaybetmişlerdir. 
Tablo 4. Birim Kök Testleri

\begin{tabular}{|c|c|c|c|c|}
\hline \multirow[b]{3}{*}{ KBGSYH } & \multicolumn{2}{|c|}{ Trend ve Sabit Terimli } & \multicolumn{2}{|c|}{ Trend ve Sabit Terimli } \\
\hline & t-istatistiği & olasılık & & LM İstatistiği \\
\hline & $-6,3127$ & 0,0001 & & 0,089287 \\
\hline GPGSYH & $-8,1023$ & 0,0000 & & $0,374028 *$ \\
\hline HPKGSYH & $-5,8981$ & 0,0002 & & 0,068593 \\
\hline KRDGSYH & $-4,4011$ & 0,0081 & & 0,069342 \\
\hline DTGSYH & $-4,7343$ & 0,0037 & & $0,247512 *$ \\
\hline $1 \%$ düzey & $-4,3098$ & & $1 \%$ düzey & 0,21600 \\
\hline $5 \%$ düzey & $-3,5742$ & & $5 \%$ düzey & 0,14600 \\
\hline $10 \%$ düzey & $-3,2217$ & & $10 \%$ düzey & 0,11900 \\
\hline
\end{tabular}

*durağanlık koşulunu sağlamamaktadır

Tablo 3. ve Tablo 4.'ten elde edilmiş olan sonuçlar neticesinde bazı serilerin düzeyde durağanken bazı serilerin 1. farklarında durağan oldukları sonucuna ulaşılmıştır, Tüm serilerin aynı düzeyde durağan olmamaları halinde Johansen veya Engle Granger gibi eşbütünleşme testleri kullanılamamaktadır. Serilerin düzey ve 1. farklarda durağan olabildiği ancak hiç birinin durağanlık için 2. düzeye ihtiyaç duymadığ 1 durumlarda Pesaran ve Shin (1999) ile Pesaran vd, (2001) tarafindan literatüre kazandırılmış olan "sınırlar testi" (Autoregressive Distributed Lag - ARDL) en uygun eşbütünleşme testidir (Ghildiyal vd, 2015).

\section{ARDL Sinırlar Testi}

ARDL yaklaşımı, p'nin Vektör Otoregresif (VAR) modeli olarak uygulanır. Eşbütünleşme testinde kullanılan ARDL yaklaşımında aşağıdaki form uygulanmıştır;

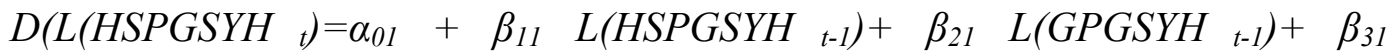
$L\left(\right.$ KBGSYH $\left._{t-1}\right)+\beta_{41} L\left(\right.$ KRDGSYH $\left._{t-1}\right)+\beta_{51} L\left(D T G S Y H_{t-1}\right)+\sum_{i=1}^{p} \alpha_{1 i} D\left(L\left(H S P G S Y H_{t-}\right.\right.$

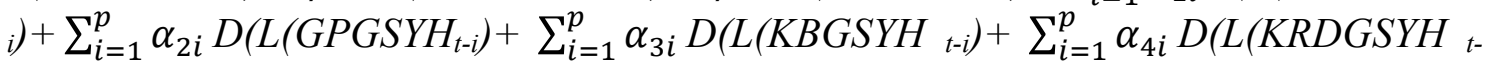
i) $+\sum_{i=1}^{p} \alpha_{5 i} D\left(L\left(D T G S Y H_{t-i}\right)+\phi_{i}\right.$ trend $+\varepsilon_{1 t}$

(2)

Denklemde KBGSYH, GPGSYH, HSPGSYH, KRDGSYH ve DTGSYH değişkenler, L logaritma operatörü, D birinci fark ve $\varepsilon$ hata terimini temsil etmektedir. Üstte verilmiş olan denklemde $\mathrm{H}_{0}$ hipotezi eşbütünleşmenin olmadığı, alternatif hipotez ise eşbütünleşmenin olduğu yönündedir. Boş hipotez $\mathrm{F}$ testi uygulanarak test edilmiştir,

Dolayısiyla;

$\mathrm{H}_{0}=\beta_{1 \mathrm{i}}=\beta_{2 \mathrm{i}}=\beta_{3 \mathrm{i}}=\beta_{4 \mathrm{i}}=\beta_{5 \mathrm{i}}=0$

$\mathrm{H}_{1}=\beta_{1 \mathrm{i}} \neq \beta_{2 \mathrm{i}} \neq \beta_{3 \mathrm{i}} \neq \beta_{4 \mathrm{i}} \neq \beta_{5 \mathrm{i}} \neq 0$

İçin $\mathrm{i}=1,2,3,4,5$,

ARDL sınır testini uygulamadan önce, değişkenlerin uygun gecikme sırasını seçerek, ARDL F istatistiğini uygun şekilde hesaplamak ve değişkenler arasında eşbütünleşmenin var olup olmadığını test etmek ön koşuldur, F-testinin hesaplanması, gecikme uzunluğunun seçilmesine çok duyarlıdır (Ouattara 2004), Seriler yıllık olduğu 
için tüm farklara 4 gecikme uzunluğu verilmiş ve Akaike bilgi kriterinin en düşük olduğu gecikme uzunluğu uygun gecikme uzunluğu olarak belirlenmiştir. En uygun gecikme 1. farkta elde edilmiştir, Ardından inceleme kapsamında yer alan serilerde otokorelasyon problemi olup olmadığını tespit edebilmek maksadıyla gerçekleştirilen Breush-Gedfrey otokorelasyon testi sonucunda da 1 . gecikmede 2,998820 (0,2233) değeri elde edilerek seriler arasında otokorelasyon problemi olmadığı sonucuna ulaşılmıştır.

Bir sonraki adım, değişkenler arasında uzun vadede eşbütünleşme araştıran F-testi uygulamaktır. Eşbütünleşme ilişkisinde Perasan (2001)'e göre belirlenmiş olan alt ve üst sınırlar küçük seriler için uygun olmadığından çalışmadaki gibi 30-80 arası değer içeren seriler için daha doğru sonuçlar veren Narayan ve Narayan (2005)'de belirlenmiş olan sınırlar da kullanılacaktır. Elde edilen F istatistiği Perasan (2001) ve Narayan ve Narayan (2005)'de verilen sınırların altında kalmışsa herhangi bir eşbütünleşme olmadığ incelenen seriler arasındaki uzun dönemli eşbütünleşme ilişkisini göstermektedir. Elde edilmiş olan F istatistik değeri Perasan (2001)'a göre belirlenmiş olan üst sınırları aştığı için \%1 hata olasılığ1 ve Narayan ve Narayan (2005)'e göre göre belirlenmiş olan üst sınırları aştığı için \%5 hata olasılığı ile seriler uzun dönemde eşbütünleşik ve dengededir denilebilir.

Tablo 5. ARDL Sınır Testi Sonuçları

Değişkenler

F ìstatistiği

\begin{tabular}{lcccc}
\hline \hline f(HSPGSYH / DTGSYH KBGSYH KRDGSYH GPGSYH) & \multicolumn{4}{c}{$6,149349 *$} \\
\hline Kritik Değerler & Pesaran (2001) & Narayan (2005) \\
$1 \%$ & Alt Sınır & Üst Sınır & Alt Sınır & Üst Sınır \\
$5 \%$ & 3,07 & 4,44 & 4,768 & 6,67 \\
$10 \%$ & 2,26 & 3,48 & 3,354 & 4,774 \\
\hline
\end{tabular}

*\%1 ve $\% 5$ anlamlılık düzeyinde

\section{Granger Uzun Dönem ve Kısa Dönem Nedensellik Testi}

Aşağıda yer alan denklemde verilen $\left(\mathrm{HSPGSYH}_{\mathrm{t}}\right)$ için uzun dönemli ARDL (1, 1, 1, 1, 1) modelini kullanarak değişkenler arasındaki uzun dönem denge ilişkisi hesaplanmıştır. Burada temel amaç, KBGSYH, GPGSYH, KRDGSYH ve DTGSYH'nin, HSPGSYH oranı üzerindeki marjinal etkilerini incelemektir.

$$
\begin{gathered}
L\left(\text { HSPGSYH }_{t}\right)=\alpha_{0}+\sum_{i=1}^{p} \alpha_{1 i} L\left(\operatorname{HSPGSYH}_{t-i}\right)+\sum_{i=1}^{q} \alpha_{2 i} L\left(\text { KBGSYH }_{t-i}\right)+\sum_{i=1}^{q} \alpha_{3 i} \\
L\left(G P G S Y H_{t-i}\right)+\sum_{i=1}^{q} \alpha_{4 i} L\left(\text { KRDGSYH }_{t-i}\right)+\sum_{i=1}^{q} \alpha_{5 i} L\left(D T G S Y H_{t-i}\right)+\phi_{i} \text { trend }+\varepsilon_{t}
\end{gathered}
$$

Üstte verilmiş olan denkleme göre HSPGSYH için Tablo 6.'da uzun dönem katsayıları verilmiştir. Elde edilen katsayılar KBGSYH (kişi başı düşen GSYH) ve GPGSYH (M2 Geniş para arzının GSYH'ya oran1) açısından \%1 önem düzeyinde anlamlı iken KRDGSYH (Özel sektör kredilerinin GSYH'ya oranı) ve DTGSYH (Dış ticaretin GSYH'ya oranı) açısından anlamsız çıkmıştır, Bu sonuçlar çerçevesinde ekonomik büyüme ve M2 geniş para arzı ile hisse senedi piyasası kapitalizasyonu arasında önemli bir nedensellik söz konusuyken, özel sektör kredileri ve toplam diş ticaret rakamları ile hisse senedi piyasası kapitalizasyonu arasında uzun dönemde herhangi bir nedensellik olmadığı sonucuna ulaşılmaktadır. 
Tablo 6. ARDL Yaklaşımı İle Tahmini Uzun Dönem Katsayılar

\begin{tabular}{lccc} 
Değișken & Katsayı & t-istatistiği & Olasıllı \\
\hline \hline C & 5,441238 & 9,96264 & $0,0000^{*}$ \\
\hline DTGSYH & 0,114560 & 0,895165 & 0,3800 \\
\hline KBGSYH & 0,977679 & 1,11445 & $0,0000^{*}$ \\
\hline KRDGSYH & $-0,034598$ & $-0,725516$ & 0,4755 \\
\hline GPGSYH & $-0,551806$ & $-2,64010$ & $0,0146^{*}$ \\
\hline TREND & 0,022874 & 3,76386 & $0,001^{*}$ \\
\hline
\end{tabular}

Kısa dönem parametreleri hata düzeltme terimi (ECT) kullanılarak tahmin edilmiştir, Hata düzeltme modelinde uzun dönem nedensellik hata düzeltme teriminin (ECT) değerinin negatif ve anlamlı olması ile ortaya çıkar, kısa dönem nedensellik ise diğer regresör değişkenlerin önem değeri ile gösterilmiştir, Aşağıda verilmiş olan enküçük kareler (OLS) denklemi ARDL $(1,2,3,4,5)$ çerçevesinde kısa dönem nedensellik için test edilmiştir;

$D\left(L\left(H S P G S Y H_{t}\right)\right)=\alpha_{0}+\sum_{i=1}^{p} \alpha_{1 i} D\left(L\left(H S P G S Y H_{t-i}\right)\right)+\sum_{i=1}^{q} \alpha_{2 i} D\left(L\left(K B G S Y H_{t-}\right.\right.$ $\left.\left.{ }_{i}\right)\right)+\sum_{i=1}^{q} \alpha_{3 i} D\left(L\left(G P G S Y H_{t-i}\right)\right)+\sum_{i=1}^{q} \alpha_{4 i} D\left(L\left(K R D G S Y H_{t-i}\right)\right)+\sum_{i=1}^{q} \alpha_{5 i} D\left(L\left(D T G S Y H_{t-}\right.\right.$ i) $)+\alpha E C T_{t-1}+\phi_{i}$ trend $+\varepsilon_{t}$

Denklemde $\alpha_{1 i}, \alpha_{2 i}, \alpha_{3 i}, \alpha_{4 i}$ ve $\alpha_{5 i}$ modelin denge yakınsamasının kısa dönem dinamik katsayılarını belirtir ve düzeltme hızı $\alpha$ ile gösterilir.

Kısa dönem sonuçları Tablo 7.'de gösterilmiştir. Elde edilmiş olan sonuçlar kısa süreli dinamiklerin, gecikmeli hata düzeltme teriminin (ECT) değeri ve işareti ile gösterildiği gibi uzun vadeli ilişkilerle bağlantılı olduğu açıkça görülmektedir. Hata düzeltme teriminin negatif ve $\% 1$ önem düzeyinde anlamlı olması da bağımlı değişkenlerle regresörler arasında bir ilişkinin varlığını göstermektedir, Bu sonuç aynı zamanda bozulmaların \%38,6'l1k bölümünün bir sonraki dönemde dengeye geleceğini göstermektedir, Bununla birlikte tablodan elde edilmiş olan değerler toplam diş ticaret rakamları (DTGSYH) ile geniş para arzının (GPGSYH) kısa vadede hisse senedi piyasası kapitalizasyonu üzerinde önemli ancak negatif bir etkiye sahipken, kişi başı gayrisafi yurtiçi hasıla (KBGSYH) ve özel sektör tarafından kullanılan kredilerin (KRDGSYH) hisse senedi piyasası kapitalizasyonu üzerinde önemli ve pozitif etkide bulunduğunu göstermektedir.

Tablo 7. Kısa Dönem Hata Düzeltme Modeli Tahmin Sonuçları

\begin{tabular}{lccc} 
Değişken & Katsayı & t-İstatistiği & Olasılık \\
\hline \hline D(LOGDTGSYH) & $-0,195158$ & $-2,293249$ & 0,0313 \\
\hline D(LOGKBGSYH) & 0,608877 & 9,591627 & 0,0000 \\
\hline D(LOGKRDGSYH) & 0,202087 & 2,584508 & 0,0166 \\
\hline D(LOGGPGSYH) & $-0,361162$ & $-4,049749$ & 0,0005 \\
\hline Trend & $-0,002979$ & $-2,949796$ & 0,0072 \\
\hline ECT(-1) & $-0,386445$ & $-3,000366$ & 0,0064 \\
\hline R2 & 0,948595 & & \\
\hline Düzeltilmiș R & 0,935185 & & 0,000000 \\
\hline F İstatistiği & $7,073,832$ & &
\end{tabular}


Elde edilmiş olan model tanısal kontroller açısından da tüm testleri geçmiştir, $\mathrm{R}^{2}$ değerinin 0,948595 (Düzeltilmiş $\mathrm{R}^{2}$ değeri 0,935185) bulunmuş olması, bağımlı değişkenin yaklaşık olarak \%95'lik kısmının model tarafından kalan kısmının ise hata terimi tarafından temsil edildiğini göstermektedir, Durbin-Watson (DW) istatistiğinin 1,816141 olarak bulunması sahte regresyon sorunu olmadığını göstermektedir, Tablo 8.'de gösterilmiş olan testlerden, Durbin Watson ve Breusch-Godfrey testleri seri korelasyon yönünden, Jarque-Bera testi normallik ile ilgili ve Heteroskedasticity testi de sabit varyansın varlığı ile ilgili çalışma kapsamında herhangi bir problem olmadığını göstermektedir.

Tablo 8. Tanımlayıcı İstatistikler

\begin{tabular}{lll}
\hline & $\boldsymbol{X}^{\mathbf{2}}$ & Olasıllk \\
\hline \hline Breusch-Godfrey Seri Korelasyon Testi & 2,99882 & 0,2233 \\
\hline Heteroskedasticity testi & 5,504735 & 0,3574 \\
\hline Jarque-Bera testi & 1,373501 & 0,503209 \\
\hline
\end{tabular}

Pesaran ve Pesaran (1997)'de parametre durağanlığını test etmek için, yinelemeli artıkların birikimli toplamı (CUSUM) ve yinelemeli artıkların birikimli toplamlarının karesi (CUSUMSQ) testlerini önermişlerdir. Literatürde CUSUMSQ testi CUSUM testine göre çok daha hassas ölçüm yapan bir testtir, bu nedenle çalışmada CUSUMSQ testi grafiği verilmiştir, CUSUM ve CUSUMSQ istatistikleri yinelemeli olarak tekrarlanır ve kesme noktalarına karşı grafikler çizilir, eğer test neticesinde elde edilecek grafik \%5 önem düzeyinde sınırlar içerisinde kalıyorsa katsayı tahminlerinin stabil olduğu söylenebilir (Bahmani-Oskooee ve Bohl 2000), CUSUMSQ testinden elde edilmiş olan sonuçlar Grafik 6.'da verilmiştir, İnceleme kapsamındaki verilerden oluşan grafik \%5 önem düzeyinde alt ve üst sınırlar içerisinde kaldığ 1 için modelin stabil olduğunu söylemek mümkündür.

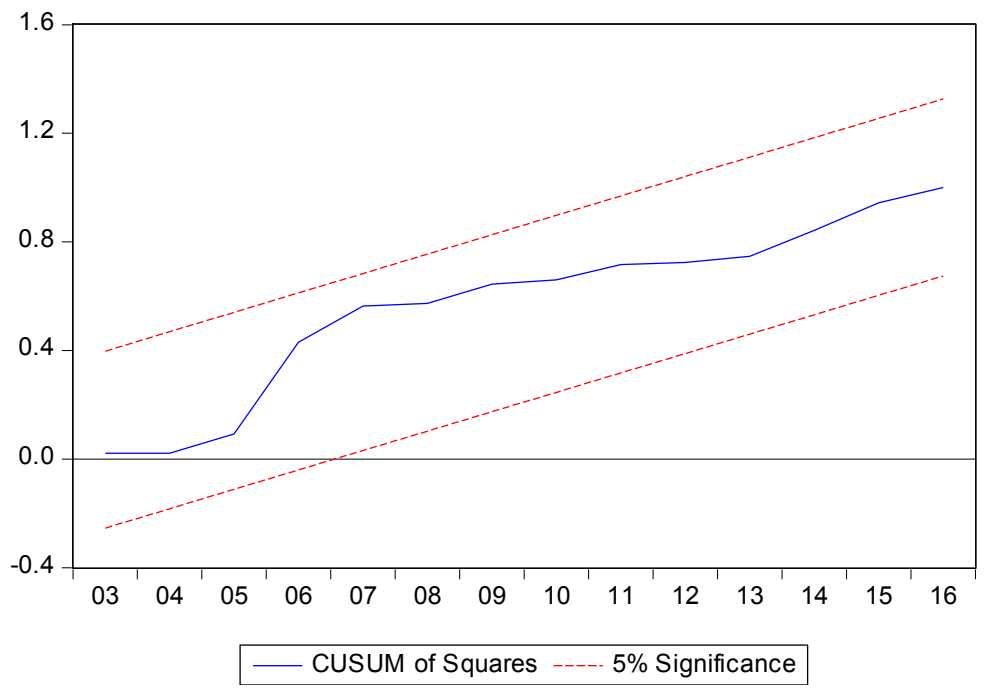

Grafik 6, CUSUMSQ testi

Tablo 9. Değişkenler arasındaki kısa dönemli Granger nedensellik ilişkilerini göstermektedir. Gayrisafi yurtiçi hasıla ve para arzından hisse senedi piyasası gelişimine doğru iki yönlü bir nedensellik vardır. Benzer şekilde özel sektör kredilerinden toplam dış ticarete yönelik tek yönlü bir nedensellik varken, para arzı ile toplam dış ticaret arasında iki yönlü bir nedensellik vardır, kısa vadede toplam kredileri 
etkileyen herhangi bir nedensellik yoktur, gayrisafi yurtiçi hasıladan geniş para arzına yönelik de tek yönlü bir nedensellik vardır. Ortaya çıkmış olan sonuçlar önceki çalışmalarla da tutarlılık göstermektedir.

Tablo 9. Block Exojenite Wald testi

HSPGSYH DTGSYH KRDGSYH KBGSYH GPGSYH Nedenselliğin Yönü

\begin{tabular}{|c|c|c|c|c|c|c|}
\hline HSPGSYH & - & 0,99 & 0,54 & $8,27 *$ & $16,14^{*}$ & $\begin{array}{l}\text { KBGSYH } \rightarrow \text { HSPGSYH; } \\
\text { GPGSYH } \rightarrow \text { HSPGSYH }\end{array}$ \\
\hline DTGSYH & $8,09 *$ & - & $5,49 * *$ & 0,00 & $4,48 * *$ & $\begin{array}{l}\text { HSPGSYH } \rightarrow \text { DTGSYH; } \\
\text { KRDGSYH } \rightarrow \text { DTGSYH; } \\
\text { GPGSYH } \rightarrow \text { DTGSYH }\end{array}$ \\
\hline KRDGSYH & 0,58 & 0,15 & - & 1,14 & 0,00 & --------- \\
\hline KBGSYH & $80,5^{*}$ & 1,31 & 0,30 & - & 0,01 & HSPGSYH $\rightarrow$ KBPGSYH \\
\hline GPGSYH & $49,79 *$ & $3,35 * * *$ & 0,29 & $2,96 * * *$ & - & $\begin{array}{l}\text { HSPGSYH } \rightarrow \text { GPGSYH; } \\
\text { DTGSYH } \rightarrow \text { GPGSYH; } \\
\text { KBGSYH } \rightarrow \text { GPGSYH }\end{array}$ \\
\hline
\end{tabular}

$* \% 1, * * \% 5, * * * \% 10$ önem derecelerini göstermektedir.

\section{Sonuçlar ve Tartışma}

$\mathrm{Bu}$ çalışmada ekonomik büyümenin finnansal gelişme üzerine etkisini bulmak maksadıyla Borsa İstanbul'un kurulduğu yıl olan 1986 yılından 2016 yılına kadarki süreçte Türkiye'nin ekonomik büyümesi ve finansal gelişimi arasında kısa ve uzun vadeli ilişkiler incelenmiştir. $\mathrm{Bu}$ dönem Türkiye açısından sermaye piyasalarının gelişim ve büyüme dönemidir, Çalışma kapsamında yer alan verilere ADF ve KPSS birim kök testleri yaptığımızda bazı verilerin düzeyde durağanken bazı serilerin 1 . farklarında durağan oldukları sonucuna ulaşılmıştır. Bunun üzerine böyle durumlarda kullanılan en uygun yöntem olan ARDL sınır testi uygulanmıştır. Elde edilen sonuçlar Minier (2003) ile Rioja ve Valev (2004)'in çalışmalarında elde edilen sonuçların aksine, incelenen tüm değişkenlerin Shahbaz vd (2008), Goldsmith (1969), Levine ve Zervos (1998), Boubakari ve Jin (2010), Ghildiyal vd, (2015) çalışmalarından elde ettikleri sonuca paralel şekilde finansal gelişme ile ekonomik büyüme ilişkisinin pozitif korelasyon içerisinde olduğu yani uzun vadede eşbütünleşik ve denge durumunda olduklarını göstermiştir.

Uzun vadeli nedensellik ilişkileri incelendiğinde ekonomik büyüme ve para arzı ile hisse senedi piyasası gelişimi arasında önemli bir nedensellik ilişkisi varken, özel sektör kredileri ve dış ticaret rakamları ile hisse senedi piyasası gelişimi arasında uzun dönemde herhangi bir nedensellik olmadığ 1 sonucuna ulaşılmaktadır. Kısa dönemli hata düzeltme modeli (ECT) sonuçlarına göre de kısa dönemde bozulan ilişkilerin ancak $\% 38,6$ 'l1k kısmı bir sonraki dönemde tekrar dengeye gelmektedir.

Kısa dönemli Granger Block Exojenite Walt Testi açısından gayrisafi yurtiçi hasıla ve para arzından hisse senedi piyasası gelişimine doğru iki yönlü bir nedensellik vardır. Benzer şekilde özel sektör kredilerinden toplam dış ticarete yönelik tek yönlü bir nedensellik varken, para arzı ile toplam dıș ticaret arasında iki yönlü bir nedensellik vardır. Kısa vadede toplam kredileri etkileyen herhangi bir nedensellik yokken, GSYH'dan geniş para arzına yönelik de tek yönlü bir nedensellik ilişkisi bulunmuştur. Schumpeter (1911)'de ortaya atılmış olan ekonomik büyümeden finansal gelişime doğru bir akış olması açısından çalışmadan elde edilen sonuçlar hipotezi 
desteklememektedir. Çalışma neticesinde ortaya çıkan sonuçlar uzun vadede eşbütünleşik olan verilerin kısa vadede Schumpeter (1911)'de ortaya atılan görüşler yerine Lewis (1954)'de ortaya atılan görüşlere daha yakın olduğu, ekonomik büyümeden finansal gelişime doğru bir akış yerine, karşılıklı bir etkileşim içinde oldukları sonucunu ortaya çıkarmıştır. Konu ile ilgili olarak Türkiye özelinde gerçekleştirilmiş olan bu çalışma benzer verilerle tüm gelişmekte olan piyasalar için birlikte uygulanabilirse gelişmekte olan piyasalara yatırım yapacak olan yatırımcıların çeşitlendirme firsatlarını görebilmeleri açısından daha yararlı olabilecektir.

\section{Kaynakça}

Altunç, Ö, F, (2008), “Türkiye'de Finansal Gelişme ve İktisadi Büyüme Arasındaki Nedenselliğin Ampirik Bir Analizi”, Eskişehir Osmangazi Üniversitesi İIBF Dergisi, 3(2): 113-127.

Ayvaz Kızılgöl, Ö.,(2011), “Mevsimsel Eşbütünleşme Testi: Türkiye’nin Makroekonomik Verileriyle Bir Uygulama", Atatürk Ünv. İIBF Dergisi, 25(2):13-25

Boubakari, A, ve Jin, D, (2010), “The Role of Stock Market Development in Economic Growth: Evidence from Some Euronext Countries", International Journal of Financial Research, 1, 14-20

Bahmani-Oskooee M, and Bohl M, T,,(2000), “German Monetary Unification and The STability of the German M3 Money Demand Function", Economics Letters, Cİlt 66, Say1,2,

Bryan J, Dettrey \& Harvey D, Palmer (2015) "Partisan Differences in the Distributional Effects of Economic Growth: Stock Market Performance, Unemployment, and Political Control of the Presidency", Journal of Elections, Public Opinion and Parties, 25:3, 317-332

Ghildiyal, V,, Pokhriyal, A,,K, ve Mohan A,, (2015), "Impact of Financial Deepening on Economic Growth in Indian Perspective: ARDL Bount Testing Approach to Coentegration", Asian Development Policy Review, 3(3):49-60,

Goldsmith R, W, (1969), "Financial Structure and Development", New Haven, CT: Yale University Press,

Gökdeniz, İ, M, Erdoğan ve K, Kalyüncü (2003), “Finansal Piyasaların Ekonomik Büyümeye Etkisi ve Türkiye Örneği (1989-2002)”, Gazi Üniversitesi Dergisi, 1, 101- 117,

Kirkpatrick, C, (2000), "Financial Development, Economic Growth and Poverty Reduction", Pakistan Development Review, 3(4): 363-388,

Korajczyk, R, A, (1996), "A Measure of Stock Market Integration for Developed and Emerging Markets", World Bank Economic Review, 10(2), ss, 267-289,

Kwiatkowski, D, Phillips, P, Schmidt, P. and Shin, Y., (1992), "Testing the Null Hypothesis of Stationarity Against the alternative of a Unit Root: How Sure Are We That Economic Time Series Have a Unit Root?", Journal of Econometrics, 54, Say1. 1-3, p, 159-178,

Levine R, ve Zervos S, (1998), "Stock Markets, Banks and Economic Growth", The American Economic Review, Vol,88, No,3

Lewis, W, A, (1954), "Economic Development with Unlimited Supplies of Labour", The Manchester School, 22: 139-191, doi:10,1111/j,1467-9957,1954,tb00021,x

Lucas, R, E, (1988), "On the Mechanics of Economic Development", Journal of Monetary Economics, 22(1), 3-42, 
Meier, G,M, ve Seers, D, (1984), "Pioneers in Development" New York, Oxford University Press, ss. $223-245$,

Metin, İ, (2016), "Dijital Pazarlama Araçlarının KOBİ'lerin İhracatına Etkisi”, Journal of Human Sciences, 13 (3), 4697-4709,

Minier, J, (2003), “Are Small Stock Markets Different?" Journal of Monetary Economics 50:1593-1602,

N' Zue, F, (2006), "Stock Market Development and Economic Growth: Evidence from Cote D' Ivoire”, Africa Development Review 18(1): 123-143,

Narayan, S, ve Narayan, P, K, (2005) "An Empirical Analysis of Fiji's Import Demand Function", Journal of Economic Studies, Vol, 32 Issue: 2, pp,158-168

Okeke, B,C, ve Acha I,,(2017), "Impact of Economic Growth on Financial Development in Nigeria (1987 - 2004)", Innovative Journal of Business, Management and Economics, Say1 1, No, 1, SS,20-28

Onwumere, J, U, J, Ibe, I, G,, Okafor, R, G, and Uche, U, B, (2012), "Stock Market and Economic Growth in Nigeria: Evidence From the Demand Following Hypothesis", European Journal of Business and Management,4(19): 1-10.

Ouattara B,(2004), "Foreign Aid And Fiscal Policy in Senegal", Unpublished manuscript, University of Manchester, Manchester, UK,

Özcan, B,, ve Arı, A,, (2011), "Finansal Gelişme ve Ekonomik Büyüme Arasındaki İlişkinin Ampirik Analizi: Türkiye Örneği”, Business and Economics Research Journal, Vol,2, No,1, SS,121-142,

Patrick, H,T, (1966), "Economic Development and Cultural Change" University of Chicago Press, , Vol, 14, No, 2, SS, 174-189

Pesaran, M,H, ve Pesaran B, (1997), "Microfit 4,0: Interactive Econometric Analysis", Oxford: Oxford University Press,

Pesaran, M, and Shin, Y, (1999), “An Autoregressive Distributed Lag Modelling Approach to Cointegration Analysis", In Strom, S, (Eds), Paper Presented at Econometrics and Economics Theory in the 20th Century: The Ragnar Frisch Centennial Symposium, Cambridge University Press, Cambridge,

Pesaran, M, Shin Y, ve Smith, R,, (2001), "Bounds testing approaches to the analysis of level relationships", Journal of Applied Econometrics, 16(3): 289326 ,

Rioja, F, and N, Valev (2004), "Finance and the Sources of Growth at Various Stages of Economic Development", Economic Enquiry 42 (1), SS. 127-40,

Robinson, J,,(1952), "The Generalization of the Generat Theory" The Rate of interest and other essays, London; Macmillian, SS,67-142,

Schumpeter, J, (1911), "A Theory of Economic Development", Cambridge, MA: Harvard University Press,

Shahbaz, M, Nadeem A,,ve Liaquat A, (2008), "Stock Market Development and Economic Growth: ARDL Causality in Pakistan" International Research Journal of Finance and Economics, Say1 14,

Stern, N, (1989), "The Economics of Development: A Survey", The Economic Journal, 99(397), 597-685, doi:10,2307/2233764

Türe, H, ve Akdi, Y, (2005), "Mevsimsel Kointegrasyon: Türkiye Verilerine Bir Uygulama", 7, Ulusal Ekonometri ve İstatistik Sempozyumu, Düzenleyen: İstanbul Üniversitesi, 26-27 May1s 2005. 


\title{
Analysing of the Relation Between Stock Markets and Economic Growth in Turkey by ARDL Bound Test
}

\author{
Umut Burak GEYİKÇi \\ Manisa Celal Bayar University, Faculty of Business Administration \\ Muradiye Kampüsü, Manisa, Turkey \\ orcid.org/0000-0002-4285-2151 \\ umutburak.geyikci@cbu.edu.tr
}

\section{Extensive Summary}

\section{Introduction}

Turkish Capital Markets began to strengthen its financial structure from the middle of the 1980s with neoliberal economic policies and the opening of the Istanbul Stock Exchange (BİST) in 1986. Capital markets, which started to accelerate in the 2000 s, after the 1990 s, which are often referred to as lost years in many studies, have not yet reached the depths that exist in developed countries.

While capital markets facilitate the mobilization of savings and transform it into the capital required for economic growth, changes in the real sector are also affecting capital markets significantly. Growth in the capital markets, while reducing the cost of access to funds needed for investments, also supports the increase in foreign capital flows and existing fund sizes. From this point of view, it is possible to come across many studies investigating the relationship between economic growth and financial development.

From the perspective of the relationship between financial development and economic growth; Robinson (1952) argues that economic growth is a trend toward financial development, while Schumpeter (1911) points out that financial development is a trend toward economic growth (Özcan and Ar1, 2011). The studies carried out in the literature are basically based on four different hypotheses. The first of these; Financial development has a high impact on economic growth (Patrick, 1966), second, economic growth is an important influence on financial development (Robinson 1952), the third one is the mutual interaction between financial development and economic growth (Lewis, 1954), And the last is Lucas (1988), Meier and Seers (1984), Stern (1989) who assert that there is no interaction between them.

In order to measure the relationship between financial development and economic growth in the literature; Different measurement materials such as national income, M1, M2 and M3 money supply, bank loans, gross domestic product, private sector loans, total lending, stock market capitalization rate and their ratios to each other were used. In this study, in order to measure the effect of economic growth on the stock market, GDP, private sector loans, stock market capitalization rate, M2 broad money supply, and the ratio of total foreign trade variables to GDP are used like Gökdeniz et al. (2003), Altunç (2008), Ghildiyal et al. 
Economic growth refers to the increase in goods and services produced by an economy (Onwumeree et al., 2012). In order for economic growth to take place, foreign trade must also develop. Firmalar should find new customers with traditional and modern methods in global markets and should contribute to economic growth and increase the domestic income (Metin, 2016). An increase in the per capita income of citizens (investors) can force investors to invest in long-term financial assets in many respects through the financial system mechanism that leads to material improvements. This relationship between financial development and economic growth has been intensively studied in recent years (Okeke and Acha, 2017).

The aim of this study is to test the hypothesis that the economic growth of Schumpeter (1911) is influential on financial development, by determining the relationship between the various variables of the economy and stock capitalization rate. Investors looking for diversification opportunities in the case of such an impact on the analysis will be able to better predict the investments they will make in stock markets with the help of economic indicators in developing countries such as Turkey. On the other hand, as a result of the economic growth, the increase in the per capita income of the citizens is thought to lead them to make long term investments through the stock market. In this context, the ARDL boundary test approach used in the study was used to investigate the relationship between financial development and economic growth in terms of Turkish economy.

\section{Material and Method}

In the study, five variables were used to measure the effect of economic growth on the stock market. The stock capitalization rate represents the stock market, while the other four variables represent economic growth. The variables used in the study are;

KBGSYH; Per capita gross domestic product

GPGSYH; The ratio of M2 wide money supply to gross domestic product

HSPGSYH; This ratio, used as the "development indicator of the stock market", is the ratio of the stock market capitalization value to the gross domestic product.

KRDGSYH; This rate, which is regarded as a sign of the banking sector, is the ratio of private sector loans to gross domestic product.

DTGSYH; This ratio, which is considered as the indicator of the openness of the economy, is the ratio of total foreign trade (export + import) figures to gross domestic product.

Logarithms of all series should be taken to reduce the effect of outliers by turning the series into linear ones (Türe ve Akd1, 2005; Ayvaz Kızılgöl, 2011). The time series used in the study covers the period from 1986 to the end of 2016, the year in which the Stock Exchange Istanbul was active, with annual values. From the obtained data; The figures for KBGSYH, GPGSYH and KRDGSYH were taken from the World Bank data pool, foreign trade figures were taken from the Turkish Statistical Institute (TURKSTAT) and M2 wide money figures were taken from the Central Bank of the Republic of Turkey (CBT).

In line with the research objectives, the following model has been established;

Financial development $=\mathrm{f}(\mathrm{KBGSYH})$ 
The econometric form of the above model is formed as follows;

$$
\underset{\beta_{4} \mathrm{GTGSYH}_{\mathrm{t}}+\mathcal{E t}}{\mathrm{HSPGSH}_{\mathrm{t}}=} \quad \alpha \quad+\beta_{1} \mathrm{GPGSYH}_{\mathrm{t}}+\quad \beta_{2} \mathrm{KBGSYH}_{\mathrm{t}}+\quad \beta_{3} \mathrm{KRDGSYH}_{\mathrm{t}}+
$$

In the equation given above; $\alpha$ is the intersection point and $\beta 1-\beta 4$ are the coefficients of the explanatory variables.

\section{Conclusion and Discussion}

In this study, short and long term relations between the economic growth and financial development of Turkey in the period from 1986, the year of the establishment of the Istanbul Stock Exchange, to the year 2016 with the aim of finding out the effect of economic growth on financial development. This period is the period of development and growth of capital markets in terms of Turkey. When we performed the ADF and KPSS unit root tests for the data in the study, while some data were found to be stationary at the level 1 and some were found to be stationary at the level. The ARDL bound test, which is the most appropriate method, used in such cases, was applied to data set. In contrast to the studies of Minier (2003) and Rioja and Valev (2004), all results, which are similarly to Shahbaz et al. (2008), Goldsmith (1969), Levine and Zervos (1998), Boubakari and Jin (2010), Ghildiyal et al. (2015), show that financial development and economic growth has positive correlation namely they are cointegrated and balanced in the long term.

When long-term causality relations are examined, there is a significant causality relationship between economic growth and money supply and stock market development, and there is no long-term causality between private sector loans and foreign trade figures and stock market development. According to the results of shortterm error correction (ECT), only $38.6 \%$ of the short-term deteriorated relations are in balance again in the next period.

From the perspective of the short-run Granger Block Exogenity Walt Test, there is a two-way causality towards the development of the stock market in terms of gross domestic product and money. Similarly, there is a one-way causality from private sector loans to total external trade, while there is a two-way causality between money supply and total foreign trade. While there is no causality affecting the total loans in the short term, there is also a one-way causality relationship between the GDP and the broad money supply. The results obtained do not support the hypothesis by Schumpeter (1911) in the sense that economic growth is a correct flow of financial growth. In conclusion, the cointegrated variables are closer to the views of Lewis (1954) instead of Schumpeter (1911) and stock market capitalization has bilateral interaction with economic growth rather than a one-way flow from economic growth to stock market capitalization. This study was carried out in Turkey. If the similar study can be applied together for all emerging markets, it may be more beneficial for investors to see the diversification opportunities in the emerging markets. 